\title{
Pensar o universo natural a partir dos regimes da imagem. 0 pensamento de Gilbert Durand ${ }^{1}$
}

\section{Thinking the natural universe from the image schemes. The thought of Gilbert Durand}

Hélène Houdayer

Pesquisadora no LERSEM/IRSA, do Departamento de Sociologia da Universidade Paul-Valéry Montpellier 3

$<\underline{\text { houdayer@sociologie.net }>}$

Texto traduzido por: Clélia Pinto

\section{RESUMO}

Propomos uma leitura do ambiente natural e físico a partir do pensamento de Gilbert Durand. O imaginário da natureza conduz à mobilização dos afetos que podem ser considerados como signos da nossa maneira de ser no mundo. É a ocasião de refletir sobre o sentido dado ao termo de meio ambiente. Uma nova postura de pesquisa deve ser igualmente reconstituída, pois não se trata unicamente de descrever as relações com a natureza, mas inventar (ou reinventar) novos tipos de negociação nas relações sociedade-natureza.

\begin{abstract}
We propose a reading of the natural and physical environment from the thought of Gilbert Durand. The imaginary of nature leads to the mobilization of affections that can be considered as signs of our way of being in the world. It is the occasion to reflect on the meaning given to the environment term. A new research position must also be reconstituted, since it is not only a question of describing relations with nature, but of inventing (or reinventing) new types of negotiation in society-nature relations.
\end{abstract}

Propomos uma leitura interativa do ambiente natural e físico a partir do pensamento de Gilbert Durand. Esse último enraíza o imaginário em um sistema de reflexos sensoriais que dão nascimento às imagens mentais. Existe uma relação entre a biologia (nossas percepções físicas) e a cultura (nossas representações) que funda o trajeto antropológico (Durand, 1960). Assim o pensamento possui uma facilidade em construir as imagens, que podem ser constantemente trabalhadas, transformadas, modelizadas em função de suas propriedades estruturais. Trata-se de um dispositivo cognitivo excepcional.

1 Conferência proferida durante o XIII Seminário Internacional da Comunicação, realizado de 17 a 19 de novembro de 2015, na Pontifícia Universidade Católica do Rio Grande do Sul (PUCRS), sob a organização do Programa de Pós-Graduação em Comunicação, coordenado pelo prof. Dr. Antonio Hohlfeldt, da Faculdade de Comunicação Social da PUCRS. 


\section{Os regimes do imaginário aplicados à natureza}

Três grandes categorias de gestos podem ajudar a nos situar no espaço das representações.

1 - O eixo postural - É principalmente ligado aos reflexos de recuperação. Ele produz imagens de separação, mas também de dominação, mobilizando as imagens de ascensão, de luz ou de claridade. Por exemplo, as armas cintilantes, o brilho do chefe, o ofuscamento do sol ou do fogo.

2 - O eixo copulativo - O modelo de base é o ato sexual. Baseado em movimentos rítmicos e cíclicos, a reversibilidade e a fecundidade. Entre os símbolos associados podemos citar: a árvore, o fruto, a semente.

3 - O eixo digestivo - Esse eixo invoca a nutrição, o calor, a intimidade, a noite. Os símbolos que o sustentam são os da água, da caverna, do ovo, do berço e também da sepultura.

A partir desses eixos dirigentes das imagens, Gilbert Durand propôs a noção de regime, segundo os princípios do isomorfismo (montagem) e de polarização (orientação) das imagens. Podemos então compreender as significações sustentadas pela natureza, seguindo esta noção de regime e de símbolos associados.

O primeiro regime é o dito como diurno. Ele está fundado sobre um sistema de oposição entre sombra e luz. É constituído de imagens que privilegiam a luz como conquista ou libertação daquilo que é associado às trevas. É um regime de contrastes que privilegia as posturas (eixos ou schèmes) ascensionais. Sua simbólica é a do combate (alcançado pelo recurso das armas).

Quando pensamos ao nosso ambiente físico, uma das imagens que se impõe à consciência é aquela de um homem que se tornou, segundo a fórmula bem conhecida, "mestre e possuidor da natureza". O homem consegue progressivamente controlar uma natureza hostil, selvagem e perigosa, contra a qual se batem os agricultores. $A$ indústria e suas técnicas inventam ferramentas cortantes, técnicas agressivas que constituem as armas para domar a natureza. 0 homem afronta uma natureza considerada como inimiga. Ela é rude, pois o clima é frequentemente amargo, o solo árido, os vegetais invasores, os animais ferozes. Hoje o homem triunfa sobre a natureza. Ele afastou os animais selvagens graças às armas, ele sabe cuidar dos espaços por meio das ferramentas cortantes, render o solo fértil graças ao adubo. A agricultura se tornou mecanizada e química. Ela permite chegar à beira dos hipermercados. A agroindústria e a genética alimentar colocam o homem em uma postura triunfante no alto da pirâmide. Ele é o herói de um sistema social que conseguiu se separar de uma natureza perigosa e desfavorável, para abrir os olhos sobre um mundo melhor e próspero, onde ele encontra a felicidade através da conquista dos elementos naturais: os 
micróbios são destruídos, os alimentos modificados, as matérias transformadas em energia. Essa sociedade se reivindica da modernidade e da razão.

$O$ regime diurno da imagem permite colocar em dia os elementos da conquista do homem sobre uma natureza física considerada hostil. $\mathrm{O}$ homem pertence à estrutura épica pela imagem do guerreiro que ele procura mostrar. Ele sai vitorioso desse enfrentamento, pois consegue dominar a natureza, domesticar os animais, tornar as terras férteis, as matérias-primas acessíveis, os recursos exportáveis. Ele incarna a estrutura heroica.

Entretanto, paralelamente a esse pensamento moderno, diversas reações se manifestaram através do tempo. A natureza evoca também outras projeções incarnadas por uma estrutura mística e romântica. O regime desta vez é noturno: a natureza das imagens são aquelas do refúgio ao seio do qual o homem tem a possibilidade de se recolher, de se esconder, de meditar; uma natureza que ele também pode completar. A estrutura é mística e romântica. $O$ homem atribui ao seu espaço virtudes protetoras e benéficas, sustentadas essencialmente por figuras românticas e utópicas. Trata-se de uma natureza poética e harmoniosa.

A natureza é considerada como hospitaleira, ela volta a ser a casa dos homens. Trata-se então de viver em harmonia a fim de melhor considerar os laços que unem os homens ao cosmo, de examinar as relações de proximidade com seu espaço natural. Uma mentalidade romântica habita os indivíduos para fundar um pensamento analógico entre "o ser e seu meio natural" (Tacussel, 2007).

Essa oposição entre um espaço natural considerado como acolhedor ou ameaçador permitehojeconsiderarnossa posição, especialmentefaceànatureza, através do schème "unir" ou "reunir" que nos leva a uma versão mais vantajosa da nossa relação com o ambiente. Os grupos estabelecem um trajeto entre as imagens de uma natureza benigna e sua hostilidade ligada ao meio. Estamos então na presença de símbolos que se nutrem das estruturas dominantes do imaginário. O meio pode ser apreendido como um conjunto de trajetos aos quais o indivíduo vai recorrer e assimilar os elementos próprios do momento vivido.

Dentro dessa ótica, é certo que a natureza continua a ser hostil, por exemplo, através do clima e suas consequências: ciclones, secas, inundações, tsunamis, que fazem dela um adversário próprio ao regime diurno. Mas parece que o homem tem sua parte de responsabilidade, pois a natureza sofre também: o descongelamento, a destruição das florestas, a perda da biodiversidade. Doravante é o homem que deve proteger a natureza cujas qualidades descobriu. O regime noturno volta com força.

O meio ambiente é um objeto de lutas e de tensões entre as conquistas do homem e seu desejo de manter uma natureza "natural" de onde retira sua 
força. Ele é "naturante", utilizando aqui a terminologia de Spinoza, aquele com que o homem pode compor (Descola, 2005). Inspirado na filosofia de Spinoza e renovado por Philippe Descola, o conceito de "natureza naturante" é constituído de instintos e de restrições (o relevo geográfico, por exemplo) com os quais é preciso transigir: agenciar as superfícies, adaptar os territórios, pensar os meios de comunicação.

Essa representação se demarca de outra aceitação da natureza "natural" enquanto apropriação pela cultura dos signos e símbolos emanados pela natureza (sua força, seu poder, sua selvageria). O caráter físico e geológico do território lembra a "natureza naturante" das origens quando o homem vivia entre os objetos propostos pela natureza. Portanto, a dimensão natural não está ausente porque certos objetos da natureza, como as árvores, são dotados de símbolos que refletem sobre os homens. Por exemplo, a força das árvores se torna um fator de proteção junto aos habitantes, mas também de esplendor.

\section{Perceber-se na natureza}

O meio ambiente, tal como nos apresenta, refere-se na sua parte semântica à ideia de meio físico. É aí que intervém a natureza. Nós encontramos uma filiação com as ciências naturais e com a filosofia, assim como uma dimensão ecológica característica da proteção do meio percebido como ameaçado (poluição, degradação, etc.) e então a proteger. O meio ambiente torna-se então uma categoria de ação pública. Numa perspectiva sociológica, a imagem que evocamos é mediação: ela nos coloca em relação com a finalidade de provocar reações sociais: desejo de consumo ou receio de contaminação participam de um modo de amparar-se dos problemas ambientais a fim de que as pessoas possam orientar-se. É no quadro da contaminação e da relação com a intoxicação que descobrimos a presença do sanitário no social: o tóxico engolido, integrado, inalado... contamina o corpo individual e em seguida o social. Cada um percebe que a vida pode ser uma relação estreita com seu corpo. As noções de "exposição", de "bioacumulação", de "susceptibilidade individual", envolvendo os produtos tóxicos no organismo formam o contorno de uma atenção crescente às normas ambientais. As doenças psicossomáticas, as alergias, os cansaços, as dores de cabeça, os problemas de pele, as inflamações, as vertigens etc., fazem parte dessas novas doenças ambientais, exponenciais, para as quais não temos solução, pois parece impossível não poder entrar em relação com o meio ambiente.

A leitura noturna da natureza permite apreciar seus valores benfeitores: força, vitalidade, energia, mas, também, a calma e a doçura. A comida e os 
alimentos permitem sentir suas vantagens e suas qualidades: o saudável, o bom, o belo. Existe uma publicidade na França sobre "frutas e legumes feios": são os alimentos desqualificados, não calibrados e disformes, por consequência, vendidos mais baratos. As pessoas compram estes produtos chamados "feios" em razão de seus preços baixos e seu aspecto engraçado. Nas publicidades as cenouras são encurvadas com duplas raízes, mas as cores são vivas, a pele brilhante e saudável. O lado estético é, então, preservado. Nisso a natureza é uma categoria existencial que possui a experiência dos sentidos. $\mathrm{O}$ meio ambiente se torna fenomenológico: seus componentes sensíveis, suas cores, seus cheiros, suas paisagens e seus animais são apreciados. O selvagem já não incomoda mais, pois ele é o indício de uma reconciliação possível entre natureza e cultura. Existe aí um imaginário coletivo que se alimenta da oposição entre o selvagem e o doméstico (Moscovici, 1974) para reencantar o mundo (Maffesoli, 2007).

De maneira que as pessoas se pronunciam a favor de uma reinserção do homem numa natureza que não está mais submetida, onde elas não procuram mais se apropriar de seus elementos, a não ser para fins humanos e sociais: a natureza é fator de coesão, ela reúne, ela veicula a interação, ela cria os laços. A sociedade não arranca mais os recursos da natureza, mas ela os contempla, ela os valoriza numa forma estética (a paisagem) e ética (os valores defendidos). Os grupos se organizam com certas qualidades tentando respeitar a origem da natureza no tempo e no espaço. Os indivíduos e as comunidades são convidados a tomar posição face aos elementos que os colocam em relação com um meio ambiente sensível, imediatamente perceptível e que faz nascerem as emoções. Assim eles se transformam em defensores da natureza imediata, pois é ela que constitui a qualidade de vida e o estilo de vida do ponto de vista local.

Por isso é necessário levar em consideração as formas de orientação dos atores da nossa sociedade frente ao meio ambiente: são eles que condicionam as práticas sociais e significações nas suas vidas, ou seja, no cotidiano. Antes de pensar ou de agir, os indivíduos e os grupos devem poder orientar-se em função do que lhes rodeia e dos meios pelos quais eles agem. $\mathrm{O}$ afetivo, então, tem um papel essencial: organizar as percepções frente ao meio ambiente. Possuímos uma grade de leitura operante para compreender a orientação dos indivíduos. O imaginário se impõe a nós em vários aspectos: imagens, mitos, símbolos, arquétipos, metáforas que pertencem a uma forma de pensamento criador de atos, de movimentos, de reflexões e de sentidos para englobar a realidade que nos rodeia.

As estruturas do imaginário elaboradas por Gilbert Durand envolvem as partes conscientes e inconscientes do nosso ser: o sonho e a ficção misturam o irracional e o racional de tal maneira que o imaginário não se resume ao não 
racional. Ele é o universo significativo que nos rodeia e que dá sentido às nossas emoções, aos nossos pensamentos e nossos atos.

Podemos nos inspirar da sociologia de Georg Simmel através da noção de "proximidade" ou de distância com os "objetos" da natureza frequentemente qualificados de "híbridos" (Vaillancourt, 2007) para compreender melhor a dimensão socializante dos elementos naturais: um simples contato pode, às vezes, ser suficiente (um riacho, por exemplo), mas, por vezes, é preciso interagira com a natureza sobre forma de atividades (ar livre, jogos, viagens).

A primeira forma de socialização mobiliza um esquema "englobante" e mostra que o homem pode ter prazer em se aliar aos elementos naturais. $O$ meio ambiente é englobante na medida em que é percebido prioritariamente através do prisma dos objetos da natureza. Avaliar e qualificar esses objetos é delicado, todavia é provável que a natureza contribua para o bem-estar dos indivíduos (Gastaldo e Luchini, 1998). Um dos critérios mais difundidos nas representações da saúde seria o fato de se viver o mais tempo possível ao ar livre (Moser, 2003), dentro dos espaços abertos a uma natureza física.

O vegetal permite aos indivíduos se sentirem mais próximos das ideias que defendem. Trata-se das dimensões simbólicas associadas à natureza: história e recursos que enraízam os indivíduos no espaço, pois eles testemunham a existência do "vivo", do que chamamos também de "pequeno patrimônio", a floresta, a biodiversidade, carregadas de valores afetivos e simbólicos. As florestas não são simplesmente nossos pulmões, elas veiculam um passado e são encarregadas da simbologia das árvores: robustas, pacíficas, majestosas...

Os homens utilizam as dimensões físicas da natureza para comunicar e trocar. As atividades ao ar livre são práticas que permitem introduzir a dimensão socializante do espaço. Aqui a natureza é reconstituída para servir de ligação, ela é personificada: ela se torna "simpática" ou "amável", a fim de favorecer uma relação social. Dessa forma, ela pode se tornar um parceiro social que trabalha a favor da defesa da natureza.

O poder dos alimentos naturais, as frutas e os legumes, em particular, nos revitalizam e nos fornecem energia. As paisagens nutrem nossos pensamentos, os vegetais que se entremeiam aos muros e muralhas da cidade nos lembram os laços natureza-cultura. Existe aqui uma analogia entre o corpo do homem e os elementos naturais. Ao penetrar nosso organismo, a natureza torna-se fonte de vitalidade. Ela nos fecunda, ela nos faz melhores, mais próximos da nossa condição humana. O homem se mistura à natureza para haurir a inspiração e energia necessárias à sobrevivência, que não é apenas material, mas comporta também elementos sensíveis. 
Para continuar a analogia, o homem se revitaliza dentro dos elementos naturais, mas semeia também sua marca na natureza: ele decide as paisagens, as culturas a priorizar, as imagens que ele pensa dar às suas cidades. Ele escolhe também o que é saudável, belo e bom na natureza para se fabricar uma moral e assumir uma ética. Assim ele influencia seu meio ambiente da mesma forma que se inspira nele.

\section{Conclusão: por uma sociologia da emoção}

O imaginário nos conduz a assimilar uma emoção a partir de uma situação (e não necessariamente de uma pessoa): cenas de ação, identificações. A emoção fixa-se a um suporte: uma paisagem, um alimento, uma atividade as quais solicitam o corpo e os sentidos.

As emoções participam do debate sobre a reconciliação da cultura com a natureza, pois elas comportam dimensões mentais e corporais. Elas engajam uma modalidade de ação específica que participa de um sistema de sentidos e valores. São produtos do social no sentido em que elas correspondem a um quadro cultural normativo: o que é bom, belo, saudável. Elas são representativas de uma cultura afetiva suscetível de dar um sentido a uma ação (de proteção, de restauração ou ainda de apropriação).

Nossa época caracteriza-se por uma propensão a exprimir as emoções sob a forma de encontros, mas também por meio da técnica e das mídias (internet e tele-realidade). Elas se tornam, então, uma força social capaz de produzir uma dinâmica. O imaginário da natureza conduz à mobilização dos afetos que podem ser considerados como signos da nossa maneira de ser no mundo. É a ocasião de refletir sobre o sentido dado ao termo de meio ambiente.

De uma noção do meio ambiente que era familiar e que, apenas os geógrafos físicos continuaram a investir (o meio físico), nós somos obrigados a passar a outra noção de ambiental que nos vem da sociedade: nossos hábitos de consumo, a maneira com que nos tratamos e percebemos os riscos (avalanches, inundações, climas, genéricos etc.), o uso da técnica. O conceito de meio deve ser retomado completamente considerando-se as novas formas de interação sociedade-natureza que não foram levadas em conta até hoje (por exemplo, o barulho, o biológico).

Uma nova postura de pesquisa deve ser igualmente reconstituída, pois não se trata unicamente de descrever as relações com a natureza, mas inventar (ou reinventar) novos tipos de negociação nas relações sociedade-natureza, novas práticas a partir das técnicas e representações do meio natural. Alexandre de Humboldt mostrou de maneira precisa como o homem depende do solo, 
do clima, da vegetação, de tal maneira que se torna impossível estudar o meio ambiente sem levar em conta o impacto dos homens (característico do antropocene). Perspectiva que será retomada por Augustin Berque através do conceito de "mesologia" (Berque, 1990), visando a levar em consideração a inteligibilidade dos lugares que não separa a influência recíproca entre o homem e seu meio ambiente (físico, social e biológico).

\section{Referências}

BERQUE, Augustin. Médiance, de milieu en paysage. Paris: Belin/Reclus, 1990.

DESCOLA, Philippe. Par delà nature et culture. Paris: Gallimard, 2005.

DURAND, Gilbert. Les Structures anthropologiques de l'imaginaire. Paris: PUF, 1960.

GASTALDO, Sylviane (dir.). Méthodes d'évaluation des biens environnementaux. Louvain: De Boeck, 1998.

HOUDAYER, Hélène. L’Émotion écologique. Paris: Edilivr, 2016.

MAFFESOLI, Michel. Le Réenchantement du monde. Paris: La Table Rond, 2007.

MOSER, Gabriel; WEISS, Catherine (dir.). Espace de vie. Paris: Armand Coli, 2003.

MOSCOVICl, Serge. Hommes domestiques et hommes sauvages. Paris: Union générale d'éditions, 1974.

SIMMEL, Georg. Sociologie, études sur les formes de socialisations. Paris: PUF, 1908.

TACUSSEL, Patrick. L’Imaginaire radical. Dijon: Les Presses du réel, 2007.

VAILLANCOURT, Jean-Guy; GENDRON, Corinne. Environnement et sciences sociales. Laval: PUL, 2007.

Recebido em: 9/5/2017

Aceito em: 9/5/2017

Endereço da autora:

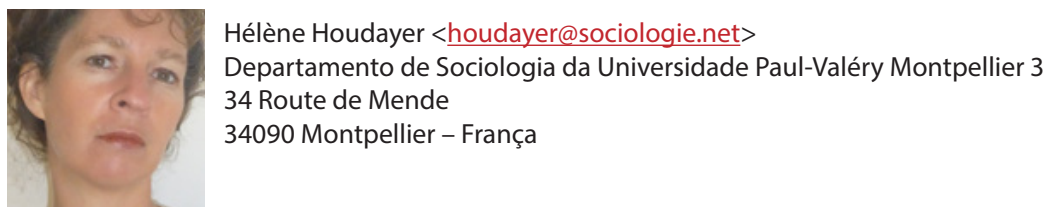

